ORIGINAL ARTICLE

\title{
Position related analysis of the appearance of and relationship between post-match physical and mental fatigue in university rugby football players
}

\author{
T Mashiko, T Umeda, S Nakaji, K Sugawara
}

Br J Sports Med 2004;38:617-621. doi: 10.1136/bjsm.2003.007690

See end of article for authors' affiliations

Correspondence to: Dr Shigeyuki Nakaji, Department of Hygiene, Hirosaki University School of Medicine, 5 Zaifu-cho, Hirosaki 036-8562, Japan; nakaji@ cc.hirosaki-u.ac.jp

Received 4September 2003 Accepted for publication 5 September 2003

\begin{abstract}
Objective: The relationship between physical and mental fatigue in rugby players after a match was examined, taking into account the position played.

Methods: The Profile of Mood State (POMS) test, blood biochemical parameters, and serum opsonic activity were measured for 37 university rugby football players before and after a match.

Results: There were no differences in parameter changes except for blood urea nitrogen la marker for protein catabolism) between the forwards and the backs. Regarding correlation between physical and mental fatigue, in forwards, changes in POMS scores showed a positive correlation with changes in the levels of enzymes of skeletal muscle origin, such as glutamate oxaloacetic transaminase (GOT) and lactate dehydrogenase (LDH), and free fatty acid (FFA) level and white blood cell count (for example, in the Total Mood Disturbance (TMD) score, Spearman's correlation coefficient was 0.417 and $p<0.05$ with GOT, 0.413 and $p<0.05$ with LDH, 0.462 and $p<0.05$ with FFA, and 0.442 and $p<0.05$ with white blood cell count). In backs, changes in the POMS scores showed a positive correlation with changes in the levels of lipid related parameters such as FFA and total cholesterol (for example, as regards the TMD score, Spearman's correlation coefficient was 0.481 and $p<0.05$ with FFA, and 0.550 and $p<0.05$ with total cholesterol), and showed a negative correlation with change in blood glucose level (TMD score, -0.517 and $\mathrm{p}<0.05$ ).

Conclusions: The different exercise loading of the position played during a rugby match may cause differences in the relationship between physical and mental fatigue.
\end{abstract}

$\mathrm{P}$ revious reports on exercise mediated fatigue in athletes demonstrated that severe exercise increases both menta and physical fatigue. ${ }^{12}$ The two main position based player groups in a rugby football match demonstrate different exercise patterns and roles, that is, the backs display an exercise pattern focussed on running and speed, in addition to some tackling, while the forwards, in addition to running and tackling, take part in scrums involving physical impact and muscular performance. Therefore, a position dependent difference might explain how physical fatigue develops during and after participation in a match. When considering the fitness of rugby football players and managing their recovery from single episode fatigue, this position dependent difference should therefore be an important concern.

The present study analysed physical and mental fatigue in university rugby players by comparing blood parameters, serum opsonic activity (SOA) to examine humoral immune function, and Profile of Mood State (POMS) scores separately for forwards and backs before and after a match. In addition, any correlations between elements of physical and mental fatigue were assessed with reference to the position played.

\section{METHODS \\ Subjects}

The subjects consisted of 37 regular players belonging to a university rugby football club ranked as one of the top clubs in Japan. Twenty players were forwards (FW group) and 17 were backs (BK group). The physical characteristics of the players were as follows: mean (standard deviation, SD) age, height, and weight of $20.3(1.5)$ years, $178.3(5.3) \mathrm{cm}$, and $87.2(8.2) \mathrm{kg}$, respectively, for the FW group; and 20.7 (1.6) years, $173.4(6.0) \mathrm{cm}$, and $72.8(7.6) \mathrm{kg}$, respectively, for the
BK group (table 1). The research was carried out in June 2000. The players' schedule consisted of rest on Monday, about $3 \mathrm{~h}$ of rugby exercise daily from Tuesday through Saturday with weight training twice or three times a week, and a match on Sunday.

Approval was obtained from the Ethics Committee of Hirosaki University School of Medicine. The study protocol and purpose were explained and informed consent was obtained from all subjects before the study.

\section{METHODS}

Investigations were carried out twice per match: first in the early morning (fasting condition) and then just after the match. Weights were accurately measured with a UC-300 digital precision scale (A \& D, Tokyo, Japan).

\section{Blood biochemical parameters}

About $10 \mathrm{ml}$ of blood were collected from the median vein of each player, $2 \mathrm{ml}$ of which was kept at room temperature for same day analysis using a Micro Biff-II blood cell autoanalyzer (Coulter, Fullerton, CA, USA) to measure white blood cell (WBC) count and hematocrit in whole blood. The remaining $8 \mathrm{ml}$ was centrifuged for $15 \mathrm{~min}$ at $3000 \mathrm{rpm}$ and the serum was separated and kept frozen at $-80^{\circ} \mathrm{C}$ until required.

Abbreviations: AUC, area under the curve; BG, blood glucose; $C K$, creatine kinase; FFA, free fatty acid; GOT, glutamate oxaloacetic transaminase; HBSS, Hanks Balanced Salt Solution; HDL-C, high density lipoprotein cholesterol; LDH, lactate dehydrogenase; PH, peak height; POMS, Profile of Mood State; ROS, reactive oxygen species; SD, standard deviation; SOA, serum opsonic activity; T-C, total cholesterol; TG, triglyceride; TMD, Total Mood Disturbance; TP, total protein; WBC count, white blood cell count 
Table 1 Characteristics of the study subjects

\begin{tabular}{lcrr}
\hline Parameter & $\begin{array}{c}\text { All players } \\
(\mathbf{n}=\mathbf{3 7})\end{array}$ & $\begin{array}{c}\text { FW players } \\
(\mathbf{n}=\mathbf{2 0})\end{array}$ & $\begin{array}{c}\text { BK players } \\
(\mathbf{n}=17)\end{array}$ \\
\hline Age (years) & $20.5(1.6)$ & $20.3(1.5)$ & $20.7(1.6)$ \\
Height $(\mathrm{cm})$ & $176.2(6.1)$ & $178.5(5.3)$ & $173.4(6.0)$ \\
Body weight $(\mathrm{kg})$ & $80.6(10.7)$ & $87.2(8.2)$ & $72.8(7.6)$ \\
\hline \multicolumn{4}{l}{ Data are expressed as the mean (SD). } \\
\end{tabular}

Serum samples were used to determine the concentrations of blood glucose (BG), total protein (TP), albumin, triglyceride (TG), free fatty acid (FFA), total cholesterol (T-C), and high density lipoprotein cholesterol (HDL-C) in order to investigate energy metabolism during exercise. Creatinine and uric acid were measured to assess exercise mediated renal function and protein metabolism. Further, to assess the degree of exercise mediated muscle tissue inflammation or injury, levels of glutamate oxaloacetic transaminase (GOT), lactate dehydrogenase (LDH), and creatine kinase (CK) were examined. In addition, to quantify the immune and antiinflammatory responses to exercise mediated stress, WBC count, immunoglobulins (IgG, IgA, IgM), and complements (C3, C4) were also measured. The following methods were used: biuret for TP; bromcresol green for albumin; enzyme for BG, TG, and TC; UV for FFA; dextran-magnesium chloride for HDL-C; UV for GOT, LDH, and CK; urease-UV for blood urea nitrogen (BUN); and turbidimetric immunoassay (TIA) for complements.

\section{Serum opsonic activity}

Blood collected in Vacutainer tubes (Becton Dickinson, Franklin Lakes, NJ, USA) was allowed to clot for $30 \mathrm{~min}$ at room temperature. The serum was then separated by centrifugation at $1500 \mathrm{~g}$ for $15 \mathrm{~min}$ and stored frozen at $-80^{\circ} \mathrm{C}$ until analysis. In this experiment we used zymosan from Saccharomyces cerevisiae, a well known activator of the alternative pathway of the complement system. Zymosan A (Sigma, St Louis, MO, USA) was suspended in Hanks Balanced Salt Solution (HBSS) at a concentration of $5 \mathrm{mg} /$ $\mathrm{ml}$ and opsonisation performed by adding control serum to a final concentration of $13 \%$ and incubating at $37^{\circ} \mathrm{C}$ for $30 \mathrm{~min}$. The particles were then washed twice with HBSS and resuspended to $5 \mathrm{mg} / \mathrm{ml}$ for lucigenin dependent chemiluminescence. In this study, we used one chemiluminigenic probe, lucigenin, to detect reactive oxygen species (ROS) activity. Lucigenin was prepared by dissolving bis- $N$-methylacridinium nitrate (Sigma) in HBSS to a final concentration of $0.26 \mathrm{mg} / \mathrm{ml}$ at $\mathrm{pH} 7.4$. Prepared opsonised zymosan suspension was added to each well of black flat bottom microplates (Greiner Japan, Tokyo, Japan), and $50 \mu \mathrm{l}$ of standard neutrophils added. The chemiluminescent reaction in the plates was automatically measured with a Lumi Box H-1000 (Maikurottekku Nichion, Funabashi, Japan) as previously described in detail. ${ }^{3}$ The following elements of SOA were evaluated: area under the curve (AUC), peak height ( $\mathrm{PH}$, the peak value in the response curve), and peak time (PT, the reaction time taken to reach $\mathrm{PH}$ ). Each sample was run in duplicate and values were averaged.

\section{POMS scores}

The POMS test ${ }^{4}$ was used to evaluate exercise related mental fatigue using the subscales Tension (Ten), Depression (Dep), Anger (Ang), Vigor (Vig), Fatigue (Fat), and Confusion (Con), assessed before and after a match. ${ }^{5}{ }^{6}$ POMS Total Mood Disturbance (TMD) was calculated using the following formula: $\quad \mathrm{TMD}=($ Ten+Dep+Ang+Fat+Con+100-Vig $) . \quad$ The test was administered to all players by the same trained interviewer.

\section{Statistics}

The results of blood biochemical parameters, SOA, and POMS scores were calculated as means (SD). The haemocrit level was used to adjust the other parameters for post-match dehydration. The differences between the pre- and postmatch values were statistically examined by paired $t$ test and the differences between the FW and BK groups by one way ANOVA. Correlations between the variations in blood parameters, values of SOA, and each POMS score before and after a match were tested using Spearman's Rank Order Correlation test. Each test result was considered significant at $\mathrm{p}<0.05$.

\section{RESULTS}

$\mathrm{TP}$, albumin, and FFA levels increased significantly in all subjects in both the FW and BK groups compared with the pre-match levels (pre-values) $(\mathrm{p}<0.01, \mathrm{p}<0.05$, respectively) (table 2$)$. TC decreased significantly in both groups $(\mathrm{p}<0.01$ in the FW group, $\mathrm{p}<0.05$ in the BK group). BUN decreased significantly in the BK group $(\mathrm{p}<0.05)$ but increased in the FW group $(p<0.01)$. The levels of most enzymes, such as GOT, LDH, and CK, significantly increased after the match in both groups compared with the pre-values $(p<0.01$ in each). WBC count increased significantly after the match $(\mathrm{p}<0.01)$ whereas IgA, IgM, C3, and C4 decreased significantly $(\mathrm{p}<0.01)$ compared with pre-values. As mentioned above, there were no differences in changes in blood parameters in either group.

Regarding SOA, the AUC values increased significantly compared with pre-values in both groups $(p<0.01$ in each), while no significant changes were seen in PT or PH in either group (table 3 ). In other words, there were no significant

Table 2 Changes in serum blood parameters before and after the game

\begin{tabular}{|c|c|c|c|}
\hline Parameter & & Before the game & After the game \\
\hline \multirow[t]{2}{*}{$\mathrm{TP}(\mathrm{g} / \mathrm{dl})$} & Forwards & $7.2(0.3)$ & $7.7(0.3)^{* *}$ \\
\hline & Backs & $7.1(0.3)$ & $7.7(0.4)^{\star *}$ \\
\hline \multirow[t]{2}{*}{ Albumin (g/dl) } & Forwards & $4.5(0.1)$ & $4.9(0.2)^{\star *}$ \\
\hline & Backs & $4.5(0.2)$ & $5.0(0.2)^{\star *}$ \\
\hline \multirow[t]{2}{*}{ TG (mg/dl) } & Forwards & $83.9(47.1)$ & $90.8(57.1)$ \\
\hline & Backs & $95.8(87.1)$ & $70.5(23.0)$ \\
\hline \multirow{2}{*}{ FFA (mEq/dl) } & Forwards & $0.5(0.2)$ & $0.6(0.4)^{*}$ \\
\hline & Backs & $0.4(0.1)$ & $0.6(0.3)^{*}$ \\
\hline \multirow[t]{2}{*}{$\mathrm{T}-\mathrm{C}(\mathrm{mg} / \mathrm{dl})$} & Forwards & $169.1(23.9)$ & $164.7(21.7)^{* *}$ \\
\hline & Backs & $173.9(28.5)$ & $168.2(25.5)^{*}$ \\
\hline \multirow[t]{2}{*}{$\mathrm{HDL}-\mathrm{C}(\mathrm{mg} / \mathrm{dl})$} & Forwards & $51.4(8.4)$ & $50.7(8.9)$ \\
\hline & Backs & 53.7 (12.3) & $57.1(11.4)$ \\
\hline \multirow[t]{2}{*}{ BG (mg/dl) } & Forwards & $84.4(10.0)$ & $86.3(22.0)$ \\
\hline & Backs & $84.3(9.6)$ & $97.8(28.1)$ \\
\hline Blood urea & Forwards & $16.8(2.8)$ & $17.7(2.8)^{\star * *}$ \\
\hline nitrogen $(\mathrm{mg} / \mathrm{dl})$ & Backs & $16.0(3.8)$ & $15.1(3.8)$ \\
\hline \multirow{2}{*}{ GOT (U/I) } & Forwards & $32.1(10.3)$ & $37.1(12.2)^{\star \star}$ \\
\hline & Backs & $30.1(10.3)$ & $33.9(11.6)^{* *}$ \\
\hline \multirow{2}{*}{$\mathrm{LDH}(\mathrm{U} / \mathrm{I})$} & Forwards & 486.5 (89.4) & $602.1(122.9)^{* *}$ \\
\hline & Backs & $422.9(89.4)$ & $523.3(122.9)^{\star *}$ \\
\hline \multirow[t]{2}{*}{ CK (U/I) } & Forwards & 831.8812 .31 & $965.8865 .3)^{* \star}$ \\
\hline & Backs & $562.2(388.7)$ & $676.1(436.9)^{* *}$ \\
\hline \multirow[t]{2}{*}{ WBC count $(/ \mu l)$} & Forwards & $6560.0(1208.9)$ & $9835.5(2094.9)^{* *}$ \\
\hline & Backs & $6470.6(1376.0)$ & $9665.3(2407.7)^{* *}$ \\
\hline \multirow[t]{2}{*}{$\lg G(\mathrm{mg} / \mathrm{dl})$} & Forwards & $1300.4(277.3)$ & $1292.3(269.6)$ \\
\hline & Backs & $1080.8(127.4)$ & $1094.4(141.2)$ \\
\hline \multirow[t]{2}{*}{$\lg A(m g / d l)$} & Forwards & $221.1(72.3)$ & $215.9(70.7)^{\star *}$ \\
\hline & Backs & $215.8(78.2)$ & $209.5(78.9)^{\text {** }}$ \\
\hline \multirow[t]{2}{*}{$\lg M(\mathrm{mg} / \mathrm{dl})$} & Forwards & $118.1(44.5)$ & $112.8(42.4)^{* *}$ \\
\hline & Backs & $109.6(38.1)$ & $105.3(36.8)^{\star *}$ \\
\hline \multirow[t]{2}{*}{ C3 (mg/dl) } & Forwards & $111.8(14.0)$ & $106.2(13.8)^{* * * * * *}$ \\
\hline & Backs & 102.2 (11.8) & $99.2(11.6)^{* *}$ \\
\hline \multirow{2}{*}{$\mathrm{C} 4$ (mg/dl) } & Forwards & $24.6(5.0)$ & $23.4(4.7)^{\star *}$ \\
\hline & Backs & $24.3(9.3)$ & $23.3(8.9)^{* *}$ \\
\hline
\end{tabular}


Table 3 Changes in SOA before and after the game

\begin{tabular}{llcc}
\hline Parameter & & Before the game & After the game \\
\hline AUC $\left(\times 10^{3}\right.$, & Forwards & $1076.0(233)$ & $1521.0(461)^{* *}$ \\
count) & Backs & $1059.0(333)$ & $1367.0(565)^{* *}$ \\
PH (count) & Forwards & $29.0(5.9)$ & $30.2(4.5)$ \\
PT (s) & Backs & $28.6(8.3)$ & $28.7(7.2)$ \\
& Forwards & $1945.0(170)$ & $1524.0(269)$ \\
& Backs & $1554.0(258)$ & $1545.0(323)$ \\
\hline
\end{tabular}

Data are expressed as the mean (SD).

${ }^{* *} p<0.01$, significantly different from pre-value.

differences in rates of change in $\mathrm{PH}, \mathrm{PT}$, or AUC between either group. Furthermore, there were no significant correlations between the changes in POMS scores or in AUC, PT, and $\mathrm{PH}$ in either group (data not shown).

Regarding the POMS score, Ang scores were significantly increased in the $\mathrm{BK}$ group compared with pre-values $(\mathrm{p}<0.05)$ (table 4). Con, Dep, Fat, and TMD scores increased significantly in both groups compared with pre-values $(\mathrm{p}<0.01$ in all $)$. In both groups, Vig scores significantly decreased compared with pre-values $(\mathrm{p}<0.05)$. In forwards, the changes in the POMS scores showed a positive correlation with changes in the levels of enzymes of skeletal muscle origin such as GOT and LDH, and in the FFA level and WBC counts (for example, as regards the TMD score, Spearman's correlation coefficient was 0.417 and $\mathrm{p}<0.05$ with GOT, 0.413 and $\mathrm{p}<0.05$ with LDH, 0.462 and $\mathrm{p}<0.05$ with FFA, and 0.442 and $\mathrm{p}<0.05$ with WBC counts, and as regards the Fat score, 0.417 and $\mathrm{p}<0.05$ with albumin, and 0.459 and $\mathrm{p}<0.05$ with creatinine) (table 5 ). In backs, the changes in the POMS scores showed a positive correlation with changes in the levels of lipid related parameters such as FFA and T-C (for example, as regards the TMD score, Spearman's correlation coefficient was 0.481 and $\mathrm{p}<0.05$ with FFA, and 0.550 and $\mathrm{p}<0.05$ with $\mathrm{T}-\mathrm{C}$ ), and showed a negative correlation with changes in BG level (as regards the TMD score, -0.517 and $\mathrm{p}<0.05$ ) (table 6).

\section{DISCUSSION}

Playing a rugby match is an intensive form of exercise. Coutts et al measured heart rate and blood lactate concentration and estimated energy expenditure during a competitive rugby league match for 17 semi-professional rugby players. ${ }^{7}$ The mean (SD) team heart rate was 166 (10) bpm and mean $\mathrm{VO}_{2}$ max was 81.1 (5.8)\%. Energy expenditure was approximately 7.9 MJ. Mean (SD) blood lactate concentration was 7.2 (2.5) $\mathrm{mmol} / \mathrm{l}$, with concentrations for the first half $(8.4$

\begin{tabular}{llcc}
$\begin{array}{l}\text { Table } 4 \\
\text { game }\end{array}$ & Changes in POMS scores before and after the \\
\hline Parameter & & Before the game & After the game \\
\hline Anger & Forwards & $9.1(8.3)$ & $10.5(9.5)$ \\
& Backs & $9.4(8.6)$ & $14.6(11.4)^{*}$ \\
Confusion & Forwards & $7.8(3.5)$ & $11.5(6.2)^{* *}$ \\
& Backs & $7.6(3.3)$ & $12.9(7.6)^{* *}$ \\
Depression & Forwards & $9.5(7.8)$ & $19.2(15.6)^{* *}$ \\
& Backs & $9.9(8.4)$ & $23.4(18.7)^{* *}$ \\
Fatigue & Forwards & $13.6(6.3)$ & $19.6(5.2)^{* *}$ \\
& Backs & $11.1(7.1)$ & $19.5(7.8)^{* *}$ \\
Tension & Forwards & $12.0(4.9)$ & $12.5(5.5)$ \\
& Backs & $12.7(5.3)$ & $14.6(9.4)$ \\
Vigor & Forwards & $12.9(6.9)$ & $9.6(7.3)$ \\
& Backs & $12.8(4.4)$ & $9.9(7.1)$ \\
TMD & Forwards & $139.0(28.4)$ & $163.6(35.8)^{* *}$ \\
& Backs & $137.9(30.3)$ & $175.1(54.6)^{* *}$ \\
\hline \multirow{2}{*}{ Data are expressed as the mean (SD). } \\
${ }^{*} \mathrm{p}<0.05,{ }^{* *}$ p $<0.01$, significantly different from the pre-value.
\end{tabular}

(1.8) $\mathrm{mmol} / \mathrm{l}$ ) being significantly higher than those for the second half $(5.9(2.5) \mathrm{mmol} / \mathrm{l})$. These results demonstrate that rugby league played at a semi-professional level is an extremely aerobic game with a considerable anaerobic component requiring high lactate tolerance. This is in good agreement with the results of Deutsch et al. ${ }^{8}$

In this study the changes in blood parameters before and after the game were as follows. First, acceleration of lipid metabolism was observed, namely there was a significant increase in FFA levels and a decrease in TC levels in both groups after the match. This agreed with previous studies showing that long hours of exercise accelerate lipid metabolism. ${ }^{9}{ }^{10}$ Second, enzymes in muscle cells, such as LDH, GOT, and CK, significantly increased in both groups. The reason for this may be that muscle activity associated with exercise accelerates degeneration of or injuries to muscle tissue, or alters the permeability of muscle cellular membranes and vascular walls. ${ }^{11-14}$ Third, WBC count significantly increased in both groups. This may be a stress related or antiinflammatory response. These findings show that similar changes in blood parameters were observed in both groups following the intensive exercise of a rugby match.

However, previous studies have differed regarding changes in immunoglobulin caused by sports related activities, reporting an increase, ${ }^{15}{ }^{16}$ a decrease, ${ }^{17}$ and no change. ${ }^{18}$ Regarding the relationship between exercise and complements, Dufaux et al reported that the plasma concentrations of $\mathrm{C} 3 \mathrm{a}$ and $\mathrm{C} 4 \mathrm{a}$, the degradation products of complements, increased after running for $2.5 \mathrm{~h}$. They considered that muscle injury due to intensive exercise had triggered activation of the complement system. ${ }^{19}$ Therefore, the significant decrease in IgA, IgM, C3, and C4 after the match, as observed in our current study, was assumed to have been caused by muscle injury brought about by intensive exercise. Perhaps some stress influenced by such injury suppressed the proliferation and differentiation of lymphocytes and affected their energy consumption.

SOA contributes to neutrophil bactericidal activity by accelerating the adhesion of neutrophils to opsonised substances via IgG, C3, etc, after which neutrophils engulf foreign bodies and produce ROS. Activated neutrophils initiate a "respiratory burst" leading to the production of superoxide anions $\left(\mathrm{O}_{2}{ }^{-}\right)$. In this study, we investigated ROS metabolism using lucigenin. Lucigenin is a specific detector of $\mathrm{O}_{2}{ }^{-}$, whereas luminol detects the total production of ROS including hypochlorous acid $\left(\mathrm{HOCl} / \mathrm{OCl}^{-}\right)$produced by myeloperoxidase. We measured SOA because it has been reported that changes in SOA are associated with physiological fatigue. ${ }^{20-22}$ In previous studies, Saito et $\mathrm{l}^{20}$ reported that SOA detected by lucigenin showed no change after a full marathon, though SOA detected by luminol significantly increased. Mochizuki et al ${ }^{21}$ reported that luminol detection found that SOA was significantly decreased immediately after an all-out session on the treadmill for male junior cross country skiers, but then significantly increased $1 \mathrm{~h}$ later. Naganuma et al ${ }^{22}$ reported that SOA detected with luminol was significantly decreased for male sumo wrestlers immediately after sumo practice. In this study, the AUC values were significantly increased compared with pre-values in both groups, whereas no significant changes were seen in either PT or PH in either group, showing that the changes in SOA were similar in both groups. The difference in SOA following exercise loading between this study and previous studies may be due to the different chemiluminigenic probe used (lucigenin versus luminol), or the difference in the sampling time after the completion of exercise. On the other hand, although SOA has been well correlated with IgG and C3 values in previous studies, such a correlation was not seen in this study, although the reason for this remains unclear. 


\begin{tabular}{|c|c|c|c|c|c|c|c|}
\hline & Anger & Confusion & Depression & Fatigue & Tension & Vigor & TMD \\
\hline TP & -0.096 & -0.032 & -0.155 & 0.361 & -0.014 & -0.22 & 0.008 \\
\hline Albumin & 0.126 & 0.075 & -0.157 & $0.417^{*}$ & 0.111 & -0.150 & 0.129 \\
\hline Blood urea nitrogen & 0.274 & 0.342 & 0.243 & -0.095 & 0.270 & 0.017 & 0.304 \\
\hline GOT & 0.070 & $0.463^{*}$ & $0.483^{*}$ & 0.054 & 0.116 & -0.237 & $0.417^{*}$ \\
\hline LDH & 0.207 & 0.382 & $0.457^{*}$ & 0.051 & 0.268 & -0.001 & $0.413^{*}$ \\
\hline $\mathrm{CK}$ & -0.334 & $0.413^{*}$ & $0.482^{*}$ & -0.245 & -0.101 & -0.313 & 0.174 \\
\hline BG & -0.105 & 0.120 & 0.078 & 0.225 & -0.070 & -0.068 & 0.065 \\
\hline TG & -0.155 & -0.382 & -0.291 & 0.168 & 0.025 & 0.218 & -0.273 \\
\hline FFA & 0.303 & 0.383 & $0.424^{*}$ & -0.013 & $0.412^{*}$ & -0.051 & $0.462^{*}$ \\
\hline $\mathrm{T}-\mathrm{C}$ & -0.226 & -0.253 & 0.059 & -0.115 & 0.086 & -0.047 & -0.102 \\
\hline HDL-C & 0.193 & 0.163 & 0.003 & -0.009 & -0.116 & 0.096 & 0.059 \\
\hline WBC count & 0.353 & $0.420^{*}$ & 0.208 & 0.237 & 0.279 & -0.163 & $0.442^{*}$ \\
\hline $\lg G$ & -0.001 & -0.102 & -0.123 & 0.187 & -0.153 & -0.017 & -0.062 \\
\hline $\lg A$ & 0.231 & -0.103 & -0.034 & 0.173 & 0.231 & -0.094 & 0.151 \\
\hline $\lg M$ & 0.048 & -0.319 & -0.056 & 0.272 & 0.242 & -0.254 & 0.090 \\
\hline $\mathrm{C} 3$ & -0.130 & -0.340 & -0.028 & 0.118 & 0.209 & 0.004 & -0.065 \\
\hline $\mathrm{C} 4$ & 0.135 & 0.047 & 0.334 & 0.066 & 0.318 & -0.212 & 0.330 \\
\hline
\end{tabular}

There are many studies on the efficacy of the POMS test in evaluating mental fatigue in athletes. ${ }^{156}$ The results of the present study showed significant increases in the Con, Dep, Fat, and TMD scores in both groups, suggesting that the activity of a single match induced mental fatigue. However, the physical and mental fatigue of the FW and BK groups were similar to each other.

Different blood parameter changes were only seen for BUN, which significantly decreased in the BK group $(\mathrm{p}<0.05)$ but increased in the FW group $(\mathrm{p}<0.01)$. Many previous studies have reported that highly intensive exercise causes protein catabolism in blood or tissues..$^{23-25}$ The current result showed that protein catabolism was greater in the FW than in the BK group.

One of the objectives of this study was to elucidate the relationship between physical stress (blood biochemical parameters) and mental fatigue (POMS) caused by physical activity during a single rugby football match. Consequently, our results show that the rugby football match caused subjects in both groups to experience physical and mental fatigue, and that protein catabolism was greater in the FW group than the BK group. This latter result may due to the different styles of play of the two groups, with the FW group experiencing much more contact play than the BK group.
On the other hand, in our position dependent analysis, the FW group showed a significant correlation between changes in POMS and changes in indicators for degeneration and injury of the muscle tissue (CK, GOT, and LDH) and for energy metabolism (FFA) and anti-inflammatory response (WBC count). In the BK group, such correlations were seen with energy metabolism (BG, FFA, and T-C) and antiinflammatory response (WBC count). In other words, this result suggests that in the $\mathrm{BK}$ players mental fatigue is influenced mainly by the degree of energy metabolism, as their major activity during a match is running. However in the FW group mental fatigue is likely to be influenced by protein catabolism, degeneration and injury to muscle tissue, energy metabolism, and anti-inflammatory response as in addition to running, the players sustain intense muscular impact at a high frequency.

These results suggest that (i) playing a rugby football match causes players both physical and mental fatigue, (ii) the position related difference in activity is responsible for differences in physical and mental fatigue between the FW and BK groups, and (iii) health management after a rugby football match is very important for the players and should be tailored to each player's position. In the BK group, where metabolism and energy consumption are associated with

\begin{tabular}{|c|c|c|c|c|c|c|c|}
\hline & Anger & Confusion & Depression & Fatigue & Tension & Vigor & TMD \\
\hline$T P$ & 0.113 & 0.150 & 0.117 & -0.248 & 0.056 & 0.120 & 0.047 \\
\hline Albumin & 0.108 & 0.099 & 0.049 & -0.286 & 0.092 & 0.165 & 0.007 \\
\hline Blood urea nitrogen & -0.193 & -0.310 & -0.252 & 0.056 & -0.004 & -0.151 & -0.147 \\
\hline GOT & 0.147 & 0.293 & 0.322 & -0.122 & -0.106 & -0.080 & 0.170 \\
\hline LDH & 0.239 & 0.411 & 0.419 & 0.063 & 0.110 & -0.379 & 0.351 \\
\hline $\mathrm{CK}$ & 0.114 & 0.295 & 0.348 & 0.164 & -0.129 & 0.373 & $-0.517^{*}$ \\
\hline$B G$ & $-0.493^{*}$ & $-0.652^{* *}$ & $-0.654^{* *}$ & 0.001 & -0.129 & 0.373 & $-0.517^{*}$ \\
\hline TG & 0.184 & 0.124 & 0.109 & 0.062 & 0.267 & -0.200 & 0.181 \\
\hline FFA & $0.473^{*}$ & $0.563^{*}$ & $0.512^{*}$ & -0.277 & $0.444^{*}$ & $-0.450^{*}$ & $0.481^{*}$ \\
\hline $\mathrm{T}-\mathrm{C}$ & $0.500^{*}$ & $0.532^{*}$ & $0.469^{*}$ & 0.271 & $0.512^{*}$ & $-0.473^{*}$ & $0.550^{*}$ \\
\hline HDL-C & -0.312 & -0.187 & -0.309 & 0.051 & -0.050 & 0.228 & -0.241 \\
\hline WBC count & -0.066 & 0.092 & 0.086 & 0.027 & -0.086 & -0.377 & 0.081 \\
\hline $\lg G$ & $0.458^{*}$ & 0.427 & $0.438^{*}$ & -0.216 & 0.244 & -0.097 & 0.346 \\
\hline $\lg A$ & 0.401 & 0.300 & 0.256 & 0.188 & 0.201 & -0.023 & 0.278 \\
\hline $\lg M$ & 0.264 & 0.179 & 0.140 & 0.092 & 0.200 & -0.122 & 0.195 \\
\hline $\mathrm{C} 3$ & 0.307 & 0.166 & 0.136 & 0.060 & 0.109 & -0.100 & 0.175 \\
\hline $\mathrm{C} 4$ & 0.039 & 0.016 & -0.028 & 0.200 & -0.165 & 0.253 & -0.046 \\
\hline
\end{tabular}




\section{Take home message}

The position related difference in the activity of players in a rugby football match is responsible for differences in physical and mental fatigue between the forwards and the backs and health management should be tailored to each player's position.

mental fatigue, ingestion of some swiftly acting energy source after a match is thought to be important to accelerate recovery from fatigue. In the FW group, where protein catabolism, degeneration of muscle tissue, and injury, as well as energy metabolism and consumption, are associated with mental fatigue, a positive supply of protein in addition to the energy source has been suggested as an effective means to accelerate recovery from single episode fatigue.

\section{ACKNOWLEDGEMENTS}

We sincerely appreciate the assistance and participation of the students and staff of Waseda University RFC who not only participated in the present study as subjects but fully cooperated with us throughout our research.

\section{Authors' affiliations}

T Mashiko, Department of Health and Physical Education, National Defense Medical College, Namiki 3-2, Tokorozawa, Saitama 3598513, Japan

T Umeda, S Nakaji, K Sugawara, Department of Hygiene, Hirosaki University School of Medicine, Zaifu-cho 5, Hirosaki, 036-8562 Japan Conflict of interest: none declared.

\section{REFERENCE}

1 Filaire $E$, Bernain X, Sagnol M, et al. Preliminary results on mood state, salivary testosterone:cortisol ratio and team performance in a professional soccer team. Eur J Appl Physiol $2001 ; 86(2): 179-84$.

2 Urhausen A, Kindermann W. Diagnosis of overtraining: what tools do we have? Sports Med 2002;32(2):95-102.

3 Kikuchi T, Nigawara K, Sugawara K, et al. Inhibitory factors of serum opsonic activity in serum from patients with chronic renal failure. Ren Fail 1997; 19:137-44

4 McNair DM, Losr M, Droppleman LF. Profile of mood states manual. San Diego, CA: Educational and Industrial Testing Service, 1971.
5 Raglin JS, Morgan WP, O'Connor PJ. Changes in mood states during training in female and male college swimmers. Int J Sports Med 1991;12:585-9.

6 Berglund B, Safstrom H. Psychological monitoring and modulation of training load of world-class canoeists. Med Sci Sports Exerc 1994;26(8):1036-40.

7 Coutts A, Reaburn P, Abt G. Heart rate, blood lactate concentration and estimated energy expenditure in a semi-professional rugby league team during a match: a case study. J Sports Sci 2003;21(2):97-103.

8 Deutsch MU, Maw GJ, Jenkins D, et al. Heart rate, blood lactate and kinematic data of elite colts (under-19) rugby union players during competition. I Sports Sci 1998;16(6):561-70.

9 Ranallo RF, Rhodes EC. Lipid metabolism during exercise. Sports Med 1998;26(1):29-42.

10 Durstine JL, Grandjean PW, Davis PG, et al. Blood lipid and lipoprotein adaptations to exercise: a quantitative analysis. Sports Med 2001;31(15):1033-62.

11 Nosaka K, Clarkson PM. Muscle damage following repeated bouts of high force eccentric exercise. Med Sci Sports Exerc 1995;27(9): 1263-9.

12 Schwane JA, Johnson SR, Vandenakker CB, et al. Delayed-onset muscular soreness and plasma CPK and LDH activities after downhill running. Med Sci Sports Exerc 1983;15(1):51-6.

13 Olerud JE, Homer LD, Carroll HW. Incidence of acute exertional rhabdomyolysis. Serum myoglobin and enzyme levels as indicators of muscle injury. Arch Intern Med 1976;136(6):692-7.

14 Nielsen HB, Secher NH, Kappel M, et al. Lymphocyte, NK and LAK cell response to maximal exercise. Int J Sports Med 1996;17(1):60-5.

15 Nieman DC, Hehlsen-Cannarella SL. The effects of acute and chronic exercise on immunoglobulins. Sports Med 1991;11(3):183-201.

16 Nehlsen-Cannarella SL, Nieman DC, Balk-Lamberton AJ, et al. The effects of moderate exercise training on immune response. Med Sci Sports Exerc 1991;23(1):64-70.

17 Mackinnon LT, Hooper S. Mucosal (secretory) immune system responses to exercise of varying intensity and during overtraining. Int J Sports Med 1994;15(suppl 3):S179-83.

18 Nieman DC, Tan SA, Lee W, et al. Complement and immunoglobulin levels in athlete and sedentary controls. Int J Sports Med 1989;10(2):124-8.

19 Dufaux B, Order U, Liesen H. Effect of short maximal physical exercise on coagulation, fibrinolysis, and complement system. Int J Sports Med 1991;12(suppl 1):S38-42.

20 Saito D, Nakaji S, Umeda T, et al. Effects of long-distance running on serum opsonic activity measured by chemiluminescence. Luminescence 2003;17:122-4.

21 Mochizuki M, Shiraishi M, Sugawara K et al. Changes in non-specific immunity of neutrophils by exercise loading in junior cross-country skiers (in Japanese). J Phys Fit Immunol 1993;3:54-6.

22 Naganuma S, Nakaii S, Sugawara K, et al. Changes in serum opsonic activity during camp in college sumo wrestlers (in Japanese). J Phys Fit Immunol 1993;3:61-4.

23 Plante RI, Houston ME. Exercise and protein catabolism in women. Ann Nutr Metab 1984;28(2): 123-9.

24 Klapcinska B, Iskra J, Poprzecki S, et al. The effects of sprint $(300 \mathrm{~m})$ running on plasma lactate, uric acid, creatine kinase and lactate dehydrogenase in competitive hurdlers and untrained men. J Sports Med Phys Fitness 2001;41(3):306-11.

25 Janssen GM, Degenaar CP, Menheere PP, et al. Plasma urea, creatinine, uric acid, albumin, and total protein concentrations before and after 15-, 25-, and 42-km contests. Int J Sports Med 1989;10(suppl 3):S132-8. 